\title{
High quality genome sequence and description of Enterobacter mori strain 5-4, isolated from a mixture of formation water and crude-oil
}

\author{
Fan Zhang ${ }^{1 \dagger}$, Sanbao Su ${ }^{2 \dagger}$, Gaoming Yu ${ }^{3}$, Beiwen Zheng ${ }^{4^{*}}$, Fuchang Shu ${ }^{2}$, Zhengliang Wang ${ }^{2}$, Tingsheng Xiang ${ }^{2}$, \\ Hao Dong ${ }^{5}$, Zhongzhi Zhang ${ }^{5}$, DuJie Hou ${ }^{1}$ and Yuehui She $2^{2^{*}}$
}

\begin{abstract}
Enterobacter mori strain 5-4 is a Gram-negative, motile, rod shaped, and facultatively anaerobic bacterium, which was isolated from a mixture of formation water (also known as oil-reservior water) and crude-oil in Karamay oilfield, China. To date, there is only one $E$. mori genome has been sequenced and very little knowledge about the mechanism of E. mori adapted to the petroleum reservoir. Here, we report the second E. mori genome sequence and annotation, together with the description of features for this organism. The 4,621,281 bp assembly genome exhibits a $\mathrm{G}+\mathrm{C}$ content of $56.24 \%$ and contains 4,317 protein-coding and 65 RNA genes, including 5 rRNA genes.
\end{abstract}

Keywords: Enterobacter mori strain 5-4, Formation water, Hydrocarbon degradation, Genome

\section{Introduction}

The genus Enterobacter was created by Hormaeche and Edwards in 1960 [1]. Members of the genus were isolated mostly from the environment, in particular from plants and recognized as notorious plant pathogens, but were also frequently isolated from hospitals, notably in healthcare associated infections and recognized as opportunistic pathogens [2,3]. Twenty-nine validly published species and 2 subspecies have previously been recorded in the genus Enterobacter. However, 17 of the validly named species have been subsequently reclassified as members of 11 other genera. As of Oct 2014, this genus contains only 10 species and two subspecies [4]. As of Oct, 2014, a total of 116 Enterobacter strains have been sequenced and 29 genome sequences were published [5-12], however, only one genome of $E$. mori isolated from diseased mulberry roots has been sequenced [13]. E. mori strain 5-4 is a Gram-negative, motile, rod shaped, and facultatively anaerobic bacterium, isolated from a crude-oil well. It is worthy of note that E. mori strain 5-4 is capable of

\footnotetext{
*Correspondence: zhengbw@zju.edu.cn; sheyuehui@263.net

${ }^{\dagger}$ Equal contributors

${ }^{4}$ State Key Laboratory for Diagnosis and Treatment of Infectious Diseases,

Zhejiang University, Hangzhou, China

${ }^{2}$ College of Chemistry and Environmental Engineering, Yangtze University,

Jingzhou, China

Full list of author information is available at the end of the article
}

degrading petroleum (Additional file 1). In order to elucidate comprehensive alkane degradation pathways and adaption mechanism in E. mori strain 5-4, whole-genome sequence analysis was thus conducted. Here, we present a summary classification and a set of features for E. mori strain 5-4, together with the description of the genomic sequencing and annotation.

\section{Classification and features}

A formation water sample was collected from Karamay Oilfield, Xinjiang, China, in 2012. The water sample was preserved at $-80^{\circ} \mathrm{C}$ immediately after collection and sent to the lab. E. mori strain 5-4 was isolated after cultivation on LB agar medium at $37^{\circ} \mathrm{C}$. The optimum temperature for growth is $35^{\circ} \mathrm{C}$, with a temperature range of $4-45^{\circ} \mathrm{C}$ (Table 1). Growth occurs under aerobic condition. Grows at $\mathrm{pH}$ 5.5-10.0, and optimally at $\mathrm{pH}$ 7.0. Cell morphology was examined by using scanning electron microscopy (Quanta 200, FEI Co., USA). Colonies are light yellow, smooth, circular with entire margins, with a diameter ranging $0.3-0.8 \mu \mathrm{m}$, and from 0.6 to $1.8 \mu \mathrm{m}$ long (Figure 1). Themethyl red test is negative. $\mathrm{H}_{2} \mathrm{~S}$ and indole are not produced. Casein and starch are not hydrolysed; gelatin is hydrolysed. Sorbitol, glycerol, tetradecane and hexadecane are utilized as the carbon source, while lactose, rhamnose, glucose, maltose, cellobiose, galactose, raffinose 
Table 1 Classification and general features of Enterobacter mori strain 5-4 according to the MIGS recommendations [14]

\begin{tabular}{|c|c|c|c|}
\hline MIGS ID & Property & Term & Evidence code $^{\mathrm{a}}$ \\
\hline & Classification & Domain Bacteria & TAS [15] \\
\hline & & Phylum Proteobacteria & TAS [16] \\
\hline & & Class Gammaproteobacteria & TAS $[17,18]$ \\
\hline & & Order Enterobacteriales & TAS [19] \\
\hline & & Family Enterobacteriaceae & TAS [20-22] \\
\hline & & Genus Enterobacter & $\operatorname{TAS}[20,23,24]$ \\
\hline & & Species Enterobacter mori & \\
\hline & & Strain: Strain 5-4 & IDA \\
\hline & Gram stain & Negative & IDA \\
\hline & Cell shape & Rod & IDA \\
\hline & Motility & Motile & IDA \\
\hline & Sporulation & Non-sporulating & IDA \\
\hline & Temperature range & $4-45^{\circ} \mathrm{C}$ & IDA \\
\hline & Optimum temperature & $35^{\circ} \mathrm{C}$ & IDA \\
\hline & pH range; Optimum & Unknown & IDA \\
\hline & Carbon source & Sorbitol, glycerol, tetradecane and hexadecane & IDA \\
\hline MIGS-6 & Habitat & Environment & IDA \\
\hline MIGS-6.3 & Salinity & Growth in $0 \% \sim 7 \% \mathrm{NaCl}$ & IDA \\
\hline MIGS-22 & Oxygen requirement & Aerobic & IDA \\
\hline MIGS-15 & Biotic relationship & Free living & IDA \\
\hline MIGS-14 & Pathogenicity & Unknown & IDA \\
\hline MIGS-4 & Geographic location & Karamay, China & IDA \\
\hline MIGS-5 & Sample collection & 2012 & IDA \\
\hline MIGS-4.1 & Latitude & $45^{\circ} 62^{\prime} \mathrm{N}$ & IDA \\
\hline MIGS-4.2 & Longitude & $85^{\circ} 02^{\prime} \mathrm{E}$ & \\
\hline MIGS-4.4 & Altitude & $460 \mathrm{~m}$ & IDA \\
\hline
\end{tabular}

${ }^{a}$ Evidence codes - IDA: Inferred from Direct Assay; TAS: Traceable Author Statement (i.e., a direct report exists in the literature); NAS: Non-traceable Author Statement (i.e., not directly observed for the living, isolated sample, but based on a generally accepted property for the species, or anecdotal evidence). These evidence codes are from the Gene Ontology project [25].

and sucrose are not utilized. Nitrite sodium and ammonium chloride are utilized, while nitrate sodium is not reduced. Antimicrobial susceptibility test showed that this strain is susceptible to ampicillin, tetracycline, erythromycin and gentamicin, and resistant to kanamycin.

A comparative taxonomic analysis was conducted based on the 16S rRNA nucleotide sequence. The representative 16S rRNA nucleotide sequence of Enterobacter mori strain 5-4 was compared against the most recent release of the EzTaxon-e database [26]. CLUSTAL $\mathrm{W}$ was used to generate alignments with comparative sequences collected from EzTaxon-e database [27]. The alignments were trimmed and converted to the MEGA 6.06 format before phylogenetic analysis. Phylogenetic inferences were made using Neighbor- joining method based on Tamura-Nei model within the MEGA 6.06 [28]. Phylogenetic tree indicated the taxonomic status of strain 5-2, clearly classified into the same branch with species $E$. mori type strain LMG $25706^{\mathrm{T}}$ (Figure 2).

\section{Genome sequencing information Genome project history}

E. mori strain 5-4 was selected for whole genome sequencing on the consideration of its potential relevance to microbial enhanced oil recovery (MEOR). The genome project is deposited in the Genome On Line Database and the draft genome sequence is deposited in GenBank under the accession JFHW00000000 and consists of 36 contigs. A summary of the project information and its 


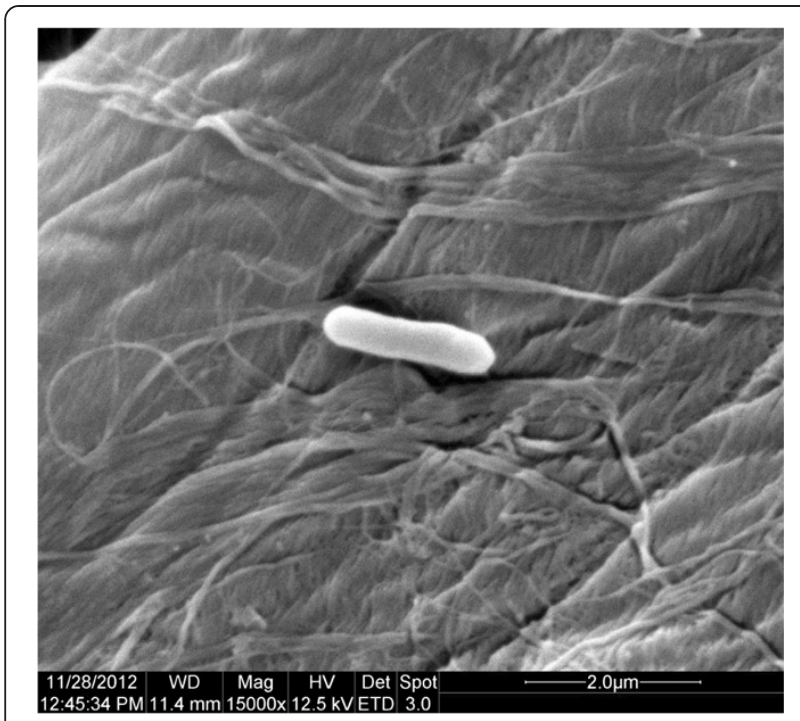

Figure 1 Scanning electron micrograph of cells of Enterobacter mori strain 5-4 bar: $2.0 \mu \mathrm{m}$.

association with MIGS version 2.0 compliance are shown in Table 2 [14].

\section{Growth conditions and DNA isolation}

E. mori strain 5-4 was grown aerobically in Luria-Bertani Broth. Cells in late-log-phase growth were harvested and lysed by EDTA, lysozyme, and detergent treatment, followed by proteinase $\mathrm{K}$ and RNase digestion. Genomic DNA was extracted using the DNeasy blood and tissue kit (Qiagen, Germany), according to the manufacturer's recommended protocol. The quantity of DNA was measured by the NanoDrop Spectrophotometer and Cubit. Then $10 \mu \mathrm{g}$ of DNA was sent to BGI (Shenzhen, China) for sequencing on a Hiseq2000 (Illumina, CA) sequencer.

\section{Table 2 Project information}

\begin{tabular}{lll}
\hline MIGS ID & Property & Term \\
\hline MIGS-31 & Finishing quality & High-quality draft \\
MIGS-28 & Libraries used & One pair-end 450 bp library \\
MIGS-29 & Sequencing platforms & Illumina HiSeq 2000 \\
MIGS-31.2 & Fold coverage & $358.0 \times$ (based on 450 bp library) \\
MIGS-30 & Assemblers & Velvet 1.2.07 \\
MIGS-32 & Gene calling method & Glimmer 3.0 \\
& Locus Tag & AA74 \\
& Genbank ID & JFHW00000000 \\
& Genbank Date of Release & April 2, 2014 \\
& GOLD ID & Gi0064796 \\
& BIOPROJECT & PRJNA224116 \\
& Project relevance & Industrial \\
MIGS-13 & Source Material Identifier & CGMCC9982 \\
\hline
\end{tabular}

\section{Genome sequencing and assembly}

Genomic DNA sequencing of E. mori strain 5-4 was performed using Solexa paired-end sequencing technology (HiSeq2000 system, Illumina). One DNA library was generated (450 bp insert size, with Illumina adapter at both end, detected by Agilent DNA analyzer 2100), then sequencing was performed with a $2 \times 100$ bp pair end sequencing strategy. Finally, a total of 6,652.30 M bp data was produced and quality control was performed with the following criteria: 1) Reads linkaged to adapters at both end were considered as sequencing artifacts then removed. 2) Bases with quality index lower than Q20 at both end was trimmed. 3) Reads with ambiguous bases $(\mathrm{N})$ were removed. 4) Single qualified reads were discarded (In this situation, one read is qualified but its mate is not). Filtered 687.39 M clean reads were assembled into scaffolds using the Velvet version 1.2.07 with parameters "-scaffolds no" [29], then we use a PAGIT flow [30] to prolong the initial contigs and correct sequencing errors to arrive at a set of improved scaffolds.

\section{Genome annotation}

Predict genes were identified using Glimmer version 3.0 [31], tRNAscan-SE version 1.21 [32] was used to find tRNA genes, whereas ribosomal RNAs were found by using RNAmmer version 1.2 [33]. To annotate predict genes, we used HMMER version 3.0 [34] to align genes against Pfam version 27.0 [35] (only pfam-A was used) to find genes with conserved domains. KAAS server [36] was used to assign translated amino acids into KEGG Orthology [37] with SBH (single-directional best hit) method. Translated genes were aligned with COG database $[38,39]$ using NCBI blastp (hits should have scores no less than 60, e value is no more than 1e-6). To find genes with hypothetical or putative function, we aligned genes against NCBI nucleotide sequence database database (nt database was downloaded at Sep 20, 2013 ) by using NCBI blastn, only if hits have identity no less than 0.95 , coverage no less than 0.9 , and reference gene had annotation of putative or hypothetical. To define genes with singnal peptide, we use SignaIP version 4.1 [40] to identify genes with signal peptide with default parameters. TMHMM 2.0 [41] was used to identify genes with transmembrane helices.

\section{Genome properties}

The draft genome sequence of $E$. mori strain 5-4 was assembled into 36 scaffolds with a assembly genome size of $4,621,281$ bp and a $\mathrm{G}+\mathrm{C}$ content of $56.2 \%\left(N_{50}\right.$ is $358,174 \mathrm{bp})$. These scaffolds contain 4317 coding sequences (CDSs), 60 tRNAs (excluding 0 Pseudo tRNAs) and incomplete rRNA operons ( 3 small subunit rRNA and 2 large subunit rRNAs). A total of 980 protein-coding genes were assigned as putative function or hypothetical proteins. 3625 genes were categorized into COGs functional 
Table 3 Genome statistics

\begin{tabular}{lrr}
\hline Attribute & Value & \% of total \\
\hline Genome size (bp) & $4,621,281$ & 100.00 \\
DNA Coding region (bp) & $4,117,467$ & 89.10 \\
DNA G + C content (bp) & $2,599,117$ & 56.24 \\
DNA scaffolds & 36 & \\
Total genes & 4,322 & 100.00 \\
Protein-coding genes & 4,317 & 99.88 \\
RNA genes & 65 & 1.51 \\
Pseudo genes & 17 & 0.39 \\
Genes with function prediction & 980 & 22.67 \\
Genes assigned to COGs & 3,625 & 83.87 \\
Genes assigned to Pfam domains & 3,995 & 92.43 \\
Genes with signal peptides & 420 & 9.72 \\
Genes with transmembrane helices & 1,085 & 25.10 \\
CRISPR repeats & 1 & 0.023
\end{tabular}

The total is based on either the size of the genome in base pairs or the total number of protein coding genes in the annotated genome. groups (including putative or hypothetical genes). The properties and the statistics of the genome are summarized in Table 3 and Table 4.

\section{Genome comparison}

Genome alignment between E. mori 5-4 (JFHW00000000) and E. mori type strain LMG 25706 T (AEXB00000000) was performed by using Mauve [42]. Orthology identification was carried out by a modified method introduced by Lerat [43]. Genome alignment showed that some functional regions are highly homologous between these two assemblies. The alignment also reveals some discrepancies between them, some short stretches of LMG 25706 T genome absent from the contigs in 5-4 (Figure 3A). However, two alkane 1-monooxygenase, one alkanesulfonate monooxygenase, one putative alkanesulfonate transporter, one putative sulfate permease and one alkanesulfonate transporter permease subunit were identified in the genome. Alkane 1-monooxygenase was found as one of the key enzymes responsible for the aerobic transformation of n-alkanes [44]. Moreover,

Table 4 Number of genes associated with the general COG functional categories

\begin{tabular}{|c|c|c|c|}
\hline Code & Value & $\%$ age & Description \\
\hline J & 202 & 4.68 & Translation, ribosomal structure and biogenesis \\
\hline A & 1 & 0.02 & RNA processing and modification \\
\hline K & 400 & 9.27 & Transcription \\
\hline L & 149 & 3.45 & Replication, recombination and repair \\
\hline B & 1 & 0.02 & Chromatin structure and dynamics \\
\hline D & 59 & 1.37 & Cell cycle control, mitosis and meiosis \\
\hline V & 146 & 3.38 & Defense mechanisms \\
\hline T & 228 & 5.28 & Signal transduction mechanisms \\
\hline M & 266 & 6.16 & Cell wall/membrane biogenesis \\
\hline N & 136 & 3.15 & Cell motility \\
\hline U & 130 & 3.01 & Intracellular trafficking and secretion \\
\hline O & 176 & 4.08 & Posttranslational modification, protein turnover, chaperones \\
\hline C & 295 & 6.83 & Energy production and conversion \\
\hline G & 499 & 11.56 & Carbohydrate transport and metabolism \\
\hline E & 604 & 13.99 & Amino acid transport and metabolism \\
\hline $\mathrm{F}$ & 94 & 2.18 & Nucleotide transport and metabolism \\
\hline $\mathrm{H}$ & 230 & 5.33 & Coenzyme transport and metabolism \\
\hline । & 120 & 2.78 & Lipid transport and metabolism \\
\hline P & 421 & 9.75 & Inorganic ion transport and metabolism \\
\hline Q & 134 & 3.10 & Secondary metabolites biosynthesis, transport and catabolism \\
\hline $\mathrm{R}$ & 720 & 16.68 & General function prediction only \\
\hline S & 361 & 8.36 & Function unknown \\
\hline- & 333 & 7.71 & Not in COGs \\
\hline
\end{tabular}

The total is based on the total number of protein coding genes in the annotated genome. 


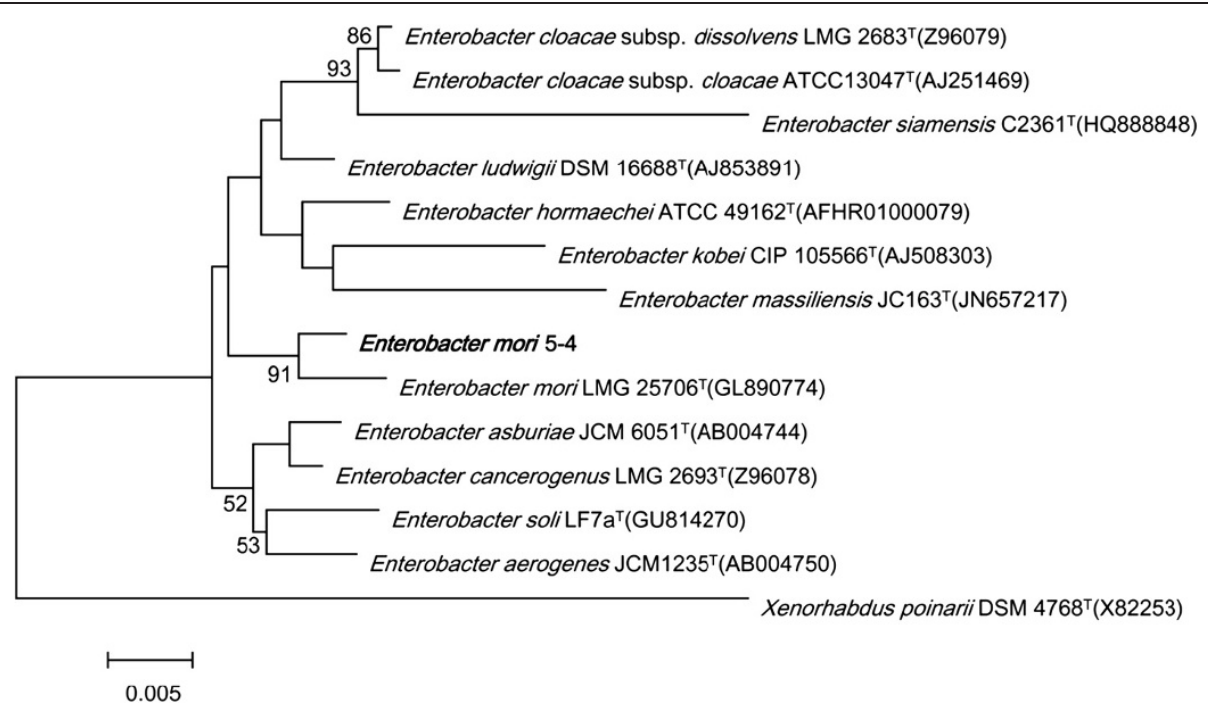

Figure 2 Phylogenetic tree highlighting the position of $E$. mori 5-4 relative to other type strains within the genus Enterobacter. The strains and their corresponding GenBank accession numbers for $16 \mathrm{~S}$ rRNA genes are shown following the organism names. Bootstrap consensus trees were inferred from 100 replicates, only bootstrap values $>50 \%$ were indicated. Xenorhabdus poinarii DSM $4768^{\top}$ was used as anoutgroup. The scale bar, 0.0005 substitutions per nucleotide position.

alkanesulfonate monooxygenase and alkanesulfonate transporter may be responsible for organosulfur compound degradation [45]. Comparison of these two strains revealed the presence of a large core-genome (Figure 3B). They shared 3555 CDS in the genome. In addition, 759 CDS from the
5-4 genome were classified as unique, while 1097 CDS from the LMG $25706 \mathrm{~T}$ genome were classified as unique. Our genomic data will provide an excellent platform for further improvement of this organism for potential application in bioremediation.

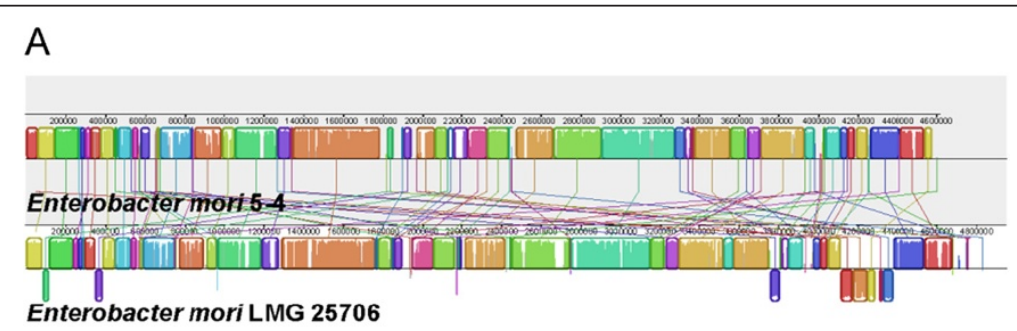

B

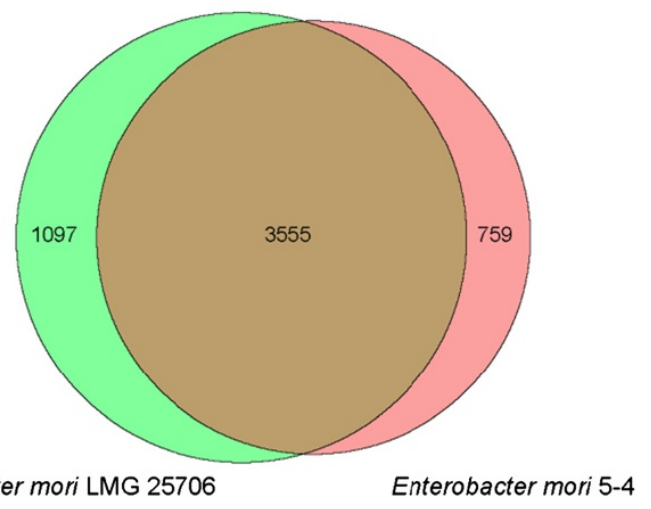

Figure 3 Genome comparison between E. mori 5-4 and E. mori LMG $25706^{\top}$. (A). Alignment is represented as local colinear blocks (colored) filled with a similarity plot. Height of the similarity plot indicates nucleotide identity of both assemblies; (B). Numbers inside the Venn diagrams indicate the number of genes found to be shared among the indicated genomes. 


\section{Conclusions}

Here, we report the second draft genome sequence and description of E. mori, which was isolated from a mixture of formation water and crude-oil. The genome revealed two alkane 1-monooxygenase, one alkanesulfonate monooxygenase, one putative alkanesulfonate transporter, one putative sulfate permease and one alkanesulfonate transporter permease subunit. Our genomic data of strain 5-4 provide a vast pool of genes involved in hydrocarbon degradation and an excellent platform for further improvement of this organism for potential application in bioremediation of oil-contaminated environments. And further comparative genomic study between stain 5-4 and other Enterobacter strains will give us a better understanding of the evolution of environmental bacteria towards industrial application.

\section{Additional file}

Additional file 1: Figure S1. Crude-oil and liquid paraffin degradation of E. mori 5-4. (A) Bio-degradation of crude-oil by E. mori 5-4 after 4-days incubation; (B) Negative control of crude-oil degradation; (C) Bio-degradation of liquid paraffin by E. mori 5-4 after 4-days incubation; (D) Negative control of liquid paraffin degradation.

\section{Competing interests}

The authors declare that they have no competing interests.

\section{Authors' contributions}

FZ, SBS, GMY, FCS and BWZ performed the microbiology and molecular biology studies; FZ, BWZ, HD, and ZLW performed the sequencing, annotation and genomic analysis; BWZ, YHS, ZZZ and TSX wrote the manuscript. All authors read and approved the final manuscript.

\section{Acknowledgements}

This study was sponsored by the National Natural Science Foundation of China (Grant No. 81301461 and No. 51474034), 863 Program (Grant No. 2013AA064402) of the Ministry of Science and Technology, Zhejiang Provincial Natural Science Foundation of China (Grant No. LQ13H190002) and the Scientific Research Foundation of Zhejiang Provincial Health Bureau (Grant No. 2012KYB083).

\section{Author details}

${ }^{1}$ The Key Laboratory of Marine Reservoir Evolution and Hydrocarbon Accumulation Mechanism, School of Energy Resources, China University of Geosciences, Beijing, China. ${ }^{2}$ College of Chemistry and Environmental Engineering, Yangtze University, Jingzhou, China. ${ }^{3}$ College of Petroleum Engineering, Yangtze University, Jingzhou, China. ${ }^{4}$ State Key Laboratory for Diagnosis and Treatment of Infectious Diseases, Zhejiang University, Hangzhou, China. ${ }^{5}$ State Key Laboratory of Heavy Oil Processing, China University of Petroleum, Beijing, China.

\section{Received: 14 May 2014 Accepted: 24 November 2014} Published: 27 February 2015

\section{References}

1. Hormaeche EEP. A proposed genus Enterobacter. Int Bull Bacteriol Nomen Taxon 1960; 10:71-74.

2. Zhu B, Lou MM, Xie GL, Wang GF, Zhou Q, Wang F, Fang Y, Su T, Li B, Duan YP. Enterobacter mori sp. nov., associated with bacterial wilt on Morus alba L. Int J Syst Evol Microbiol 2011; 61:2769-2774.

3. Mezzatesta ML, Gona F, Stefani S. Enterobacter cloacae complex: clinical impact and emerging antibiotic resistance. Future Microbiol 2012; 7:887-902.
4. Taxonomic Abstract for Enterobacter. The Namesforlife Abstracts. Garrity GM, Parker CT, Ed. NamesforLife, LLC; 2014. http://doi.org/10.1601/tx.3148.

5. Deangelis KM, D'Haeseleer P, Chivian D, Fortney JL, Khudyakov J, Simmons B, Woo H, Arkin AP, Davenport KW, Goodwin L, Chen A, Ivanova N, Kyrpides NC Mavromatis K, Woyke T, Hazen TC. Complete genome sequence of "Enterobacter lignolyticus" SCF1. Stand Genomic Sci 2011; 5:69-85.

6. Humann JL, Wildung $M$, Cheng $C H$, Lee $T$, Stewart JE, Drew JC, Triplett EW Main D, Schroeder BK. Complete genome of the onion pathogen Enterobacter cloacae EcWSU1. Stand Genomic Sci 2011; 5:279-286.

7. Humann JL, Wildung M, Pouchnik D, Bates AA, Drew JC, Zipperer UN, Triplett EW, Main D, Schroeder BK. Complete genome of the switchgrass endophyte Enterobacter clocace P101. Stand Genomic Sci 2014, 9:726-734

8. Khanna N, Ghosh AK, Huntemann M, Deshpande S, Han J, Chen A, Kyrpides N, Mavrommatis K, Szeto E, Markowitz V, Ivanova N, Pagani I, Pati A, Pitluck S, Nolan M, Woyke T, Teshima H, Chertkov O, Daligault H, Davenport K, Gu W, Munk C, Zhang X, Bruce D, Detter C, Xu Y, Quintana B, Reitenga K, Kunde $Y$, Green $L$, et al. Complete genome sequence of Enterobacter sp. IIT-BT 08: A potential microbial strain for high rate hydrogen production. Stand Genomic Sci 2013; 9:359-369.

9. Lagier JC, El Karkouri K, Mishra AK, Robert C, Raoult D, Fournier PE. Non contiguous-finished genome sequence and description of Enterobacter massiliensis sp. nov. Stand Genomic Sci 2013; 7:399-412.

10. Minogue TD, Daligault HE, Davenport KW, Bishop-Lilly KA, Bruce DC, Chain PS, Coyne SR, Chertkov O, Freitas T, Frey KG, Jaissle J, Koroleva Gl, Ladner JT, Palacios GF, Redden CL, Xu Y, Johnson SL. Draft Genome Assemblies of Enterobacter aerogenes CDC 6003-71, Enterobacter cloacae CDC 442-68, and Pantoea agglomerans UA 0804-01. Genome Announc 2014; 2:e01073-14.

11. Witzel K, Gwinn-Giglio M, Nadendla S, Shefchek K, Ruppel S. Genome sequence of Enterobacter radicincitans DSM16656(T), a plant growth-promoting endophyte. J Bacterio/ 2012; 194:5469.

12. Shin SH, Kim S, Kim JY, Lee S, Um Y, Oh MK, Kim YR, Lee J, Yang KS. Complete genome sequence of Enterobacter aerogenes KCTC 2190. J Bacteriol 2012; 194:2373-2374.

13. Zhu B, Zhang GQ, Lou MM, Tian WX, Li B, Zhou XP, Wang GF, Liu H, Xie GL, Jin GL. Genome sequence of the Enterobacter mori type strain, LMG 25706, a pathogenic bacterium of Morus alba L. J Bacterio/ 2011; 193:3670-3671.

14. Field D, Garrity G, Gray T, Morrison N, Selengut J, Sterk P, Tatusova T, Thomson N, Allen MJ, Angiuoli SV, Ashburner M, Axelrod N, Baldauf S, Ballard S, Boore J, Cochrane G, Cole J, Dawyndt P, De Vos P, DePamphilis C, Edwards R, Faruque N, Feldman R, Gilbert J, Gilna P, Glöckner FO, Goldstein P, Guralnick R, Haft D, Hancock D, et al. The minimum information about a genome sequence (MIGS) specification. Nat Biotechnol 2008; 26:541-547.

15. Woese CR, Kandler O, Wheelis ML. Towards a natural system of organisms: proposal for the domains Archaea, Bacteria, and Eucarya. Proc Natl Acad Sci 1990, 87:4576-4579.

16. Garrity GMBJ, Lilburn T. Phylum XIV. Proteobacteria phyl. nov. In Bergey's Manual of Systematic Bacteriology, Second Edition. 2 Part B. Edited by Garrity GM, Brenner DJ, Krieg NR, Staley JT. New York: Springer; 2005:1.

17. Garrity A. Validation of publication of new names and new combinations previously effectively published outside the IJSEM. Int I Syst Evol Microbiol 2005, 55:2235-2238.

18. Garrity GMBJ, Lilburn T. Class III. Gammaproteobacteria class. nov. In Bergey's Manual of Systematic Bacteriology, Second Edition, Volume 2. Edited by Brenner DJ, Krieg NR, Staley JT, Garrity GM. New York: Springer; 2005:1.

19. Garrity GMHJ. Taxonomic Outline of the Archaea and Bacteria. In Bergey's Manual of System-atic Bacteriology, Volume 1. 2nd edition. Edited by Garrity GM, Boone DR, Castenholz RW. New York: Springer; 2001:155-166.

20. Skerman VBDMV, Sneath PHA. Approved lists of bacterial names. Int J Syst Bacteriol 1980; 30:225-420.

21. Rahn O. New principles for the classification of bacteria. Zentralblatt fur Bakteriologie, Parasitenkunde, Infektionskrankheiten und Hy-giene. Abteilung II 1937; 96:273-286.

22. Commission. J. Conservation of the family name Enterobacteriaceae, of the name of the type genus, and designation of the type species OPINION NO. 15. Int Bull Bacteriol Nomend Taxon 1958; 8:73-74.

23. Hormaeche EEP. A proposed genus Enterobacter. Int Bull Bacteriol Nomend Taxon 1960 1960; 10:71-74.

24. Board. E. OPINION 28 rejection of the bacterial generic name Cloaca Castellani and Chalmers and acceptance of Enterobacter Hor-maeche and Edwards as a bacterial generic name with type species Enterobacter 
cloacae (Jordan) Hormaeche and Edwards. Int Bull Bacte-riol Nomend Taxon 1963; 13:28.

25. Ashburner M, Ball CA, Blake JA, Botstein D, Butler H, Cherry JM, Davis AP, Dolinski K, Dwight SS, Eppig JT, Harris MA, Hill DP, Issel-Tarver L, Kasarskis A, Lewis S, Matese JC, Richardson JE, Ringwald M, Rubin GM, Sherlock G. Gene ontology: tool for the unification of biology. The Gene Ontology Consortium. Nat Genet 2000; 25:25-29.

26. Kim OS, Cho YJ, Lee K, Yoon SH, Kim M, Na H, Park SC, Jeon YS, Lee JH, Yi H, Won S, Chun J. Introducing EzTaxon-e: a prokaryotic 16S rRNA gene sequence database with phylotypes that represent uncultured species. Int J Syst Evol Microbiol 2012; 62:716-721.

27. Larkin M, Blackshields G, Brown N, Chenna R, McGettigan PA, McWilliam H, Valentin F, Wallace IM, Wilm A, Lopez R. Clustal W and Clustal X version 2.0. Bioinformatics 2007; 23:2947-2948.

28. Tamura K, Stecher G, Peterson D, Filipski A, Kumar S. MEGA6: Molecular Evolutionary Genetics Analysis version 6.0. Mol Biol Evol 2013, 30:2725-2729

29. Zerbino DR, Birney E. Velvet: algorithms for de novo short read assembly using de Bruijn graphs. Genome Res 2008; 18:821-829.

30. Swain MT, Tsai IJ, Assefa SA, Newbold C, Berriman M, Otto TD. A post-assembly genome-improvement toolkit (PAGIT) to obtain annotated genomes from contigs. Nat Protoc 2012; 7:1260-1284.

31. Delcher AL, Bratke KA, Powers EC, Salzberg SL. Identifying bacterial genes and endosymbiont DNA with Glimmer. Bioinformatics 2007 23:673-679.

32. Lowe TM, Eddy SR. tRNAscan-SE: a program for improved detection of transfer RNA genes in genomic sequence. Nucleic Acids Res 1997; 25:0955-0964.

33. Lagesen $\mathrm{K}$, Hallin $\mathrm{P}$, Rødland EA, Stærfeldt H-H, Rognes T, Ussery DW. RNAmmer: consistent and rapid annotation of ribosomal RNA genes. Nucleic Acids Res 2007; 35:3100-3108.

34. Eddy SR. Accelerated Profile HMM Searches. PLoS Comput Biol 2011; 7:e1002195.

35. Punta M, Coggill PC, Eberhardt RY, Mistry J, Tate J, Boursnell C, Pang N, Forslund K, Ceric G, Clements J. The Pfam protein families database. Nucleic Acids Res 2012, 40:D290-D301.

36. Moriya Y, Itoh M, Okuda S, Yoshizawa AC, Kanehisa M. KAAS: an automatic genome annotation and pathway reconstruction server. Nucleic Acids Res 2007; 35:W182-185.

37. Kanehisa M, Araki M, Goto S, Hattori M, Hirakawa M, Itoh M, Katayama T, Kawashima S, Okuda S, Tokimatsu T, Yamanishi Y. KEGG for linking genomes to life and the environment. Nucleic Acids Res 2008; 36:D480-484

38. Tatusov RL, Natale DA, Garkavtsev IV, Tatusova TA, Shankavaram UT, Rao BS, Kiryutin B, Galperin MY, Fedorova ND, Koonin EV. The COG database: new developments in phylogenetic classification of proteins from complete genomes. Nucleic Acids Res 2001; 29:22-28.

39. Tatusov RL, Galperin MY, Natale DA, Koonin EV. The COG database: a tool for genome-scale analysis of protein functions and evolution. Nucleic Acids Res 2000; 28:33-36.

40. Petersen TN, Brunak S, von Heijne G, Nielsen H. SignalP 4.0: discriminating signal peptides from transmembrane regions. Nat Methods 2011; 8:785-786.

41. Krogh A, Larsson B, Von Heijne G, Sonnhammer EL. Predicting transmembrane protein topology with a hidden Markov model: application to complete genomes. J Mol Biol 2001; 305:567-580.

42. Mauve. http://asap.ahabs.wisc.edu/mauve/.

43. Lerat $E$, Daubin $V$, Moran NA. From gene trees to organismal phylogeny in prokaryotes: the case of the gamma-Proteobacteria. PLoS Biol 2003; 1:E19.

44. van Beilen JB, Funhoff EG. Alkane hydroxylases involved in microbial alkane degradation. Appl Microbiol Biotechnol 2007; 74:13-21.

45. Van Hamme JD, Bottos EM, Bilbey NJ, Brewer SE. Genomic and proteomic characterization of Gordonia sp. NB4-1Y in relation to 6: 2 fluorotelomer sulfonate biodegradation. Microbiology 2013; 159:1618-1628.

doi:10.1186/1944-3277-10-9

Cite this article as: Zhang et al:: High quality genome sequence and description of Enterobacter mori strain 5-4, isolated from a mixture of formation water and crude-oil. Standards in Genomic Sciences 2015 10:9.

\section{Submit your next manuscript to BioMed Central and take full advantage of:}

- Convenient online submission

- Thorough peer review

- No space constraints or color figure charges

- Immediate publication on acceptance

- Inclusion in PubMed, CAS, Scopus and Google Scholar

- Research which is freely available for redistribution

Submit your manuscript at www.biomedcentral.com/submit

C Biomed Central 